\title{
Influence of Tourism Industry Development on the Regional Labour Market (on the Example of the Yaroslavl Region)
}

\author{
Lubov Semenovna Morozova ${ }^{1}$, Alexander Nikolaevich Ananjev ${ }^{1}$, Vladimir Yurievich Morozov ${ }^{1}$, Natalya \\ Vladimirovna Havanova $^{1} \&$ Elena Vladimirovna Litvinova ${ }^{1}$ \\ ${ }^{1}$ Department of Economics and Management, Russian State University of Tourism and Service, Moscow, \\ Russian Federation \\ Correspondence: Morozova Lubov Semenovna, Department of Economics and Management, Russian State \\ University of Tourism and Service, Moscow, Russian Federation. Tel: 7-985-360-2182.
}

\author{
Received: December 20, 2014 Accepted: December 30, 2014 Online Published: February 25, 2015 \\ doi: $10.5539 /$ res.v7n3p51 \\ URL: http://dx.doi.org/10.5539/res.v7n3p51
}

\begin{abstract}
The decrease of employment level in the region and priority of developing tourism industry as a strategic factor of unemployment rate decrease are estimated in the article based on research of the current condition of Yaroslavl region labour market. It was determined that conditions of labour market and tourism industry of the Yaroslavl region are connected as complementary and interdependent functional areas. It was defined that tourism sphere has a multiplied positive effect on the employment level in the region due to increase of its functioning scope caused by relatively high shares of unoccupied population in the region. The basic development trends of the tourism industry in the Yaroslavl region characterised by positive development of a tourist infrastructure, improved quality, and outreach of services range, increase of tourist inflow in the region were designated in the research. It was found out that availability of various tourist resources in the Yaroslavl region creates conditions for many kinds of tourism: cultural and informative, cruise, medical and secondary wellness, business and event, ecological and adventure, as well as rural tourism. Taking into account results of research of the main regional features and potential, groups of development potential of the tourism industry in the Yaroslavl region were determined. Such groups include natural and geographical, culture-historical, professional and demographic, social and economic, material and technical, and economic-political potentials. The main destabilising factors of development of the regional tourism market as the base for increase of employment level in the region were summarized, and the complex of conceptual recommendations for creation of favourable conditions for formation of development potential was proposed.
\end{abstract}

Keywords: labour market, population employment, unemployment rate, tourism, tourism market, tourism industry, tourism products

\section{Introduction}

\subsection{Introduce the Problem}

Enhancement of the worldwide trend of increasing tourism sphere importance is caused by essential influence of this sphere on economy. Tourism is a significant source of income and population employment, factor-promoting realisation of international policy of a state and diversification of economy. The research urgency arises from the facts that in market conditions of economy management, spheres, and levels of tourism service are extended extremely quickly, the number of tourism organisations grows; new tourism products are being created which proves complex development of this economy branch. In this sphere, the new workplaces are distributed more widely geographically as compared to other developing economic sectors, irrespective of the state development level, and become one of the key factors for creating additional workplaces.

\subsection{Importance of the Problem}

In connection with the fact that resource possibilities of Russia regions allow developing tourism actively, thereby activating life of local population and attracting tourists from the neighbour regions and countries, the subjects relevance predetermines a scientific priority of the research for theoretical and practical reframe of interdependence between tourism industry and labour market at the state regional level. 
Therefore, reduction of potential possibilities of the tourism industry development as a priority direction of economic policy of the region using the example of Yaroslavl region is urgent for solving of the main problem when developing employment policy taking into account regional features of territorial entities of the RF. Our research is dedicated to this problem.

\subsection{Relevant Scholarship}

The analysis of research results of the leading scientists and field-specific literature shows significant theoretical development of the tourism branch functioning and its influence on economic potential of a state. Special attention should be paid to scientific researches of the Russian and foreign scientists who considered the theoretical bases of the tourism industry and management quality in the process of rendering tourism services: Saveleva (2008), Blanke (2013), Voskolovich (2010), and Chiesa (2013).

Problematics of direct influence of the tourism sphere on labour potential of state and region economy have been examined in researches of the following scientists: Gulyaeva (2012), Asalieva (2013), Akkemik (2012), Brida (2013), Vanhove (1981), Kovyneva (2005), and Hughes (2002).

At the same time, the scientists have focused mainly on essential features of tourism, background of its development. Historical aspects of the tourism industry development in developed and developing countries, its features, and influence on a state economy, interaction between the tourism industry and labour market were investigated. However, such important issues as prioritising the tourism development as a factor for employment level increase taking into account regional features, assessment of regional tourism industry development potential as backbone of the state tourism industry were studied insufficiently. They also require further conceptual development and fundamental complex research.

\subsection{State Hypotheses and Their Correspondence to Research Design}

Taking into account scientific underdevelopment of problematics, the main task of this research is reasoning of a strategic orientation of employment policy for expansion of the tourism market using the example of the Yaroslavl region, identification of background and potential of the regional tourism development for estimation of multiplied effects on employment level in the region.

Potential opportunities of the region for development of the tourism industry as a factor for increase of employment level in the Yaroslavl region were revealed and analysed in the article.

The research is devoted to solving of the following conceptual problems:

- Reasoning of priority development of the tourism in order to overcome unemployment in the Yaroslavl region as economic potential of the region;

- Analysis of the labour market condition in the Yaroslavl region and development trends of the tourism industry;

- Revealing of potential opportunities of development and expansion of the tourism market in order to ensure multiplied effect on the regional labour market;

- Generalisation of the main destructive factors of the tourism industry development in the Yaroslavl region, and formulation of conceptual recommendations set for increasing its development potential and influence on the regional labour market.

\section{Method}

\subsection{Method of Statistical Monitoring}

The reference database for estimation of condition of the labour market and the insurance market of the Yaroslavl region was created in research by means of selective statistical monitoring. The database for analysis of the regional labour market condition has been generated by scientifically organized gathering of information about quantity of the region active population, quantity of unemployed and employed people. Gathering of information about number of the tourism industry infrastructure facilities, tourists flow, rating of the region potential, competent personnel of the tourism market made it possible to create the database for tourism sphere status quantitative consideration in the Yaroslavl region.

\subsection{Method of Analysis and Measurement}

The statistical report about quantity of the active population, unemployed and employed people in the region, the number of the tourism industry infrastructure facilities, tourists flow, rating of the region potential, competent personnel of the tourism market, and analysis of dynamic processes of the labour market and the regional tourism industry within the period 2004-2012 was created using the analysis method on the basis of generated 
database with condition of the labour market and the tourism market in the Yaroslavl region. The statistical report about quantitative information allowed revealing trends and priorities of development of labour and tourism markets by calculation of their relative indicators.

The potential opportunities for expansion of the tourism market as factor of increase of the regional employment level were determined taking into account analytical processing of the quantitative indicators characterising natural and geographical, culture-historical, professional and demographic, social and economic, material and technical and economic-political features of the Yaroslavl region.

\subsection{Taxonomic Method}

Standardization of indicators of the Yaroslavl region labour and tourism markets' development in the period of 2004-2013 was carried out using taxonomic method: quantity of the active population, quantity of unemployed and employed people in the region, quantity of tourist services, quantity of tourists who have visited the region, number of travel agencies were transformed to integrated standardized measurement system. The final procedure is formation of distances matrix. Position of each specific indicator in the whole complex of investigated objects will be defined based on this matrix. The distance on each indicator is defined as a difference between the standardized value of this indicator and the standardized value of this indicator at the neighbour or reference object. In our research, the indicator's reference value has served as a comparison base for calculation of distances. The maximum value of the standardized indicator is considered the reference for incentive indicators: active population, quantity of employed people, quantity of tourist services, quantity of tourists, and quantity of travel agencies. The minimum value is considered the reference for indicators of disincentive (quantity of unemployed people).

Integrated indicators of development of the labour market and the tourism market of the Yaroslavl region in the period of 2004-20013 were calculated based on defined incentives and disincentives. This allowed determining the dynamics general trend taking into account specific factors.

\subsection{Method of Observational Generalization and Logical Inference}

The informative process of determination and designation of relatively steady features of the tourism industry functioning - increase of workplaces and generalization of potential opportunities of the Yaroslavl region as attractive region for the tourists from the natural and geographical, culture-historical, professional and demographic, social and economic, material and technical and economic-political points of view, made it possible to determine the observational fact-priority of developments of the tourism industry in order to increase the regional employment level.

Detecting of steady features of the tourism industry development according to the main indicators, such as infrastructure, quality and quantity of services, competence of the tourism sphere personnel, financial and labour potential and their scientific and theoretical underpinning, allowed revealing the factors destructive for development of the Yaroslavl region tourism branch and to propose conceptual recommendations worked out using method of logical inference and intended to promote the regional tourism branch efficiency.

\section{Results}

The problem of unemployment is pending and very important issue in market economy. It is impossible to have effective economy without solving this problem. The main feature of unemployment in Russia is its latent character. Conditions for normal functioning of the labour market are not created yet. However, one of global issues preventing increase of employment level is failure to pay attention to the regional features of the labour market taking into account development of potentially favourable fields of activity, such as the tourism industry. Another one urgent problem is lack of qualified personnel and differentiated approach to promoting labour and financial potential of a region.

The interdependence between the tourism industry and the labour market is reflected in support of employment in a state economy, i.e., the population gets a job at the tourist enterprises (hotel, transport, and so forth). Tourism growth creates new workplaces both at state and regional levels, irrespective of the region's development level. Therefore, such an impact of tourism on employment can become essential for those regions, which depend highly on this sector of economy.

The current stage of Russia development prescribes special requirements and new approaches to formation of economic potential of a specific region. According to WTO estimations, by 2020 Russia can get the 5th place of European countries which are most popular among the tourists conceding only to France, Spain, Great Britain and Italy (today the Russia takes the 13th place) (Blanke \& Chiesa, 2013). 
Share of tourism in economy of the Russian Federation (RF) is still rather small which does not allow appreciating important impact on the labour markets at both state and specific region levels. As of 2013, the tourism share makes up about $2.4 \%$ of the gross domestic product of the RF, and according to the World economic forum, Russia took only 63d place among 140 states. Whereas in 2012 the RF took the 59th place (Blanke \& Chiesa, 2013). The level of tourism industry development in the Russian Federation does not meet regions' potential opportunities and the population requirements for tourist services. Internal and inbound kinds of tourism are developed especially poorly. According to expert estimations, the Russian Federation regions use only 8-10\% of their tourism potential (Expert RA Rating agency, 2014).

The Russians tend to make much more foreign travels, and the number of travel agencies oriented on outbound tourism increases, whereas inbound and internal tourism rather are most important for economic development of the country. These types of tourism represent a favourable direction of regional specialization. Regional approach to tourism is of especially great importance for the RF, because of huge territory and considerable social, economic, and natural differences between the regions. In this connection, the article is devoted to studying of tourism potential and its influence on the labour market using the example of the Yaroslavl region.

The analysis results show that the level of population incomes in the Yaroslavl region has positive dynamics for last 13 years according to the general tendency in the RF (Figure 1) (Regional office of the Federal agency of the state statistics in the Yaroslavl region, 2014).

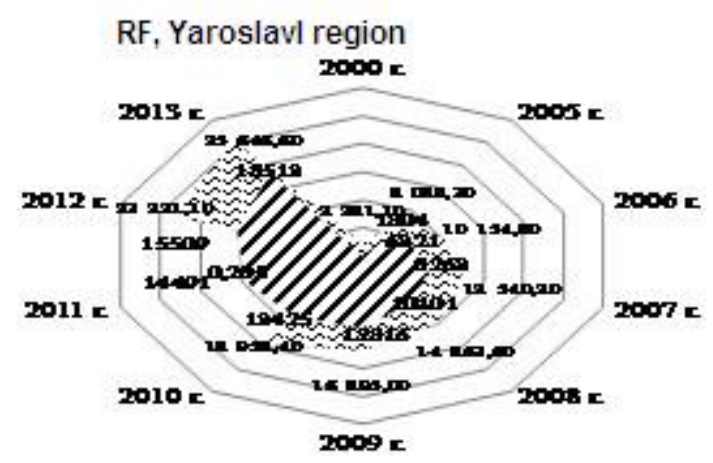

Figure 1. Dynamics of income of the population in the Russian Federation and the Yaroslavl region, thousand roubles

However, discords with a number of economically developed countries on a political basis, introduction of economic sanctions and restrictions against Russia restraining import of consumer goods, reduce density of the competitive environment in the territory of Russia. The results are growth of consumer prices in domestic market, increase of inflation expectations and decrease of real incomes of the population. Federal State Statistics Service reports that nationwide real personal income in the 1st half-year of 2014 almost did not decrease in comparison with the 1st half-year of 2013, whereas in the Central federal district the personal income was reduced by $3.5 \%$, and in the Yaroslavl region-by $3.8 \%$ (Regional office of the Federal agency of the state statistics in the Yaroslavl region, 2014). All the above-mentioned factors narrow down potentialities of the tourism market development in Volga districts of the Russian Federation. Moreover, the unemployment rate in the Yaroslavl region has almost reached the level of 2004-4.5\% at the end of 2013 which proves the tendency of employment level reduction (Figure 2) (Regional office of the Federal agency of the state statistics in the Yaroslavl region, 2014). 


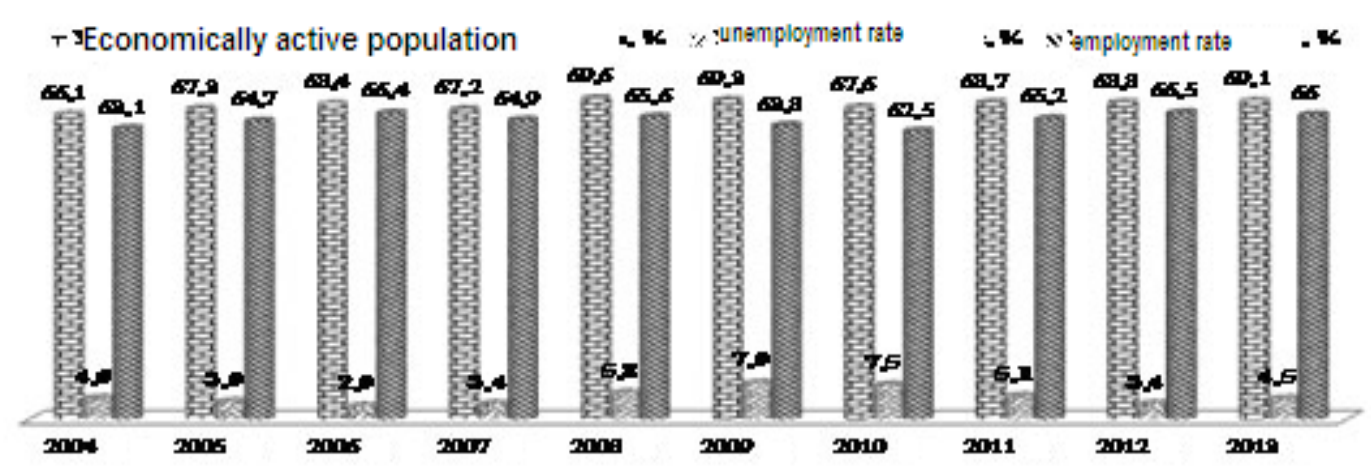

Figure 2. The main indicators of the Yaroslavl region labour market (\%)

Deterioration of situation in the labour market is caused also by disproportionality of infrastructure, which is characterized by the following features:

- Mismatch of supply and demand for human resources in the labour market from professional qualification point of view;

- Employment problems of specific categories of citizens requiring additional attention: parents with many children, women with minor children, people of pre-retirement and retirement age, certain categories of youth (without operational experience, without professional education), graduates of professional educational institutions and other categories of citizens;

- Limited sphere of occupation in company towns and remote rural territories;

- Reduction of employable population;

- Illegal labour market (16\% of gross national product) and shady employment which involves at least 13 million persons, or $17-18 \%$ of economically active population of Russia according to expert estimations (Ponomarenko, 2014).

Two state target programs were developed for improvement of condition in the labour market and maintenance of a stable situation in the Yaroslavl region. These are the regional program of additional measures for decreasing tension in the labour market in the Yaroslavl region for 2013-2015, and the departmental target program "Assistance of employment of the Yaroslavl region population" for the medium-term period of 2014-2015. Great attention is paid to development of enterprises and organizations of the tourism industry for implementation of the specified regional programs for improvement of the local population employment. Such enterprises form the important element for support of stable situation in the regional labour market (Departmental target program “Assistance of employment of the Yaroslavl region population" for 2014-2015 years, 2014).

According to Expert RA Rating agency the tourist potential is the most important among potentials of territory development in the Yaroslavl region-1.458 (Figure 3), and the 17th place of tourist potential in the RF (Expert RA Rating agency, 2014). This provides necessity to increase employment level in the region by means of the tourism industry. 


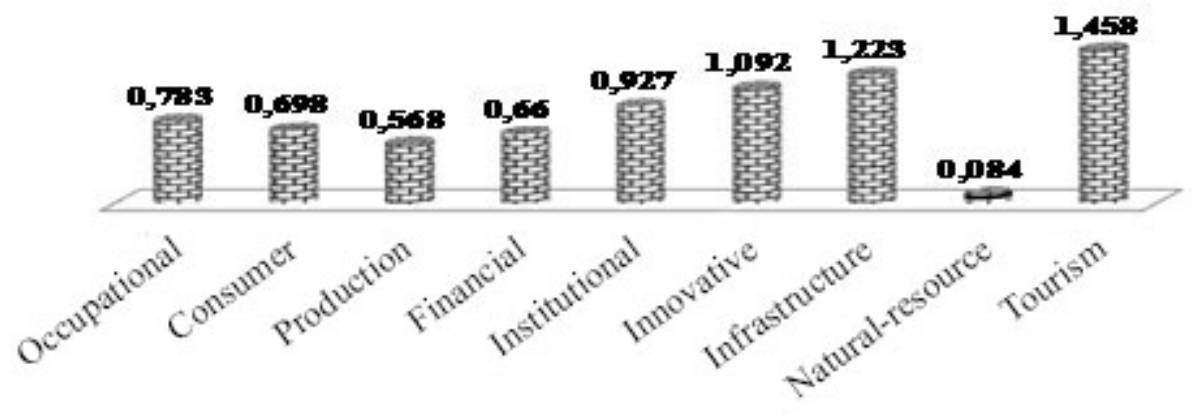

Figure 3. Rating of potentials for development of the Yaroslavl region

Development of tourism can be considered as strategic priority for increase of the employment level in the Yaroslavl region only provided there is a stable perspective growth of the tourism infrastructure and industry. Background of tourism development is potential of the region. The Yaroslavl region is located on the western margin of the Russian, or East European Plain. This is the most western region in the RF. The Yaroslavl region has big tourist potential, favourable geographical location; combines natural wealth and culture-historical heritage. Tourist activities are being profoundly developed in the Yaroslavl region for a long time. The first Russian tourist edition, "Russian tourist" magazine, was published in the Yaroslavl in 1914. Authorities of Yaroslavl, one of the first provincial towns of pre-revolutionary Russia, organized reception of sightseeing groups in an orderly way (The Federal Agency for Tourism, 2014).

The Yaroslavl region has a powerful natural and geographical potential for tourism. The Yaroslavl oblast is situated on a part of the East European Plain, in a zone of a southern taiga and mixed woods. In the north the region borders on the Vologda oblast (has access to the Rybinsk water basin), in the west-on the Tver oblast, in the south — on the Moscow, Vladimir and Ivanovo oblasts, in the east —on Kostroma oblast. The administrative centre of the region is Yaroslavl city. Large and historically important cities: Rybinsk, Tutaev, Pereslavl-Zalessky, Uglich, Rostov, Myshkin. The region includes 11 cities, 21 urban-type settlements. The main river is Volga with feeders (Korozhechna, Nerl, Volga Yukhot, and Kotorosl) and water basins-Rybinsk, Kostroma, Uglich. The largest lakes are Nero and Plasheevo. Fir forests with addition of birch and aspen prevail in the north of the region; the mixed woods of coniferous and broad-leaved trees (ash, maple, oak) grow in the south of the region. Woods take about a half of the whole territory of the Yaroslavl region. The woods are inhabited by elks, brown hares, foxes, wolves, martens; black grouses, owls, woodpeckers, hazel grouses, wood-grouses. Pereyaslav national park and a part of Darwin reserve are situated in the Yaroslavl region (Monitoring of consumption of services in the sphere of tourism business of the Yaroslavl region, 2013).

The culture-historical potential of the tourism development in the Yaroslavl region as factor for increase of employment level is characterised by availability of over 5 thousand historical and cultural landmarks in the region. This culture-historical potential is a background for systematic development of culture and educational kinds of tourism. A museum network is presented by 16 museums including 1 federal, 6 regional, 9 municipal. The largest museums were opened in the last century. Their collections include more than 800 thousand depository items (Government program of the Yaroslavl region "Development of culture and tourism in the Yaroslavl region" for 2014-2018, 2014).

The historical centre of Yaroslavl is UNESCO World Heritage Site. There are about 800 listed buildings in the city. The state museums are located in historical buildings and complexes, which are historical and cultural monuments of the federal and regional importance adapted for museum purposes. All buildings do not meet modern requirements for exhibiting and depository of museum fund items, and need to be renovated and reconstructed (Tourism Agency, 2014).

Only state museums of the region have minimum necessary scope of information and transport resources. The main fund of the state and municipal museums totals 651.6 thousand depository items. Only 2.5 percent of the main fund are presented in constant expositions; 1.05 percent of the main fund is activity used in exhibition annually (Government program of the Yaroslavl region "Development of culture and tourism in the Yaroslavl region" for 2014-2018, 2014).

Development of the tourism market in the Yaroslavl region is considerably connected with material and technical 
potential of the region. Three cities of the Yaroslavl region enter the Golden Ring of Russia. These are Yaroslavl, Rostov Veliky and Pereslavl-Zalessky. Tunoshna airport has the international status. Automobile tourism is a basis for development of secondary wellness tourism. Yaroslavl city and the whole region remains a large and important road junction for many years. The main load with automobile tourists is divided between two most popular roads: Kholmogory M8 road and Sergiev Posad-Kalyazin-Rybinsk-Cherepovets road. Yaroslavl-Ivanovo (through Zayachy Kholm) and Yaroslavl-Kostroma, which earlier entered into the Golden Ring are auxiliary roads.

The hotel infrastructure develops quickly which is connected with significant increase of a tourist flow within the last years. Two years ago, the regional department of economic development with the assistance of German advisers has developed the plan for building of hotels and increase of room supply taking into account tourist flow growth. The plan is calculated for the period until 2020. 8 new hotels with 750 hotel beds were completed in 2011 as a part of the plan implementation. As of 2013, there are 183 hotels with 10.4 thousand hotel beds in the region. In general, the growth of hotel beds number exceeds $10 \%$ for two consecutive years now. This is one of the highest indicators in the Central federal district of Russia (Department of the tourism development in the Yaroslavl region, 2014).

Sport enterprises represent another one important part of leisure industry. One of factors promoting development of sports leisure is availability of many water resources and possibility to create conditions for formation of tourism product, which is new for the Yaroslavl region and is based on aquatics (yachting, water ski etc.).

Transport services (13.1\%), telecommunication services (17.6\%), public services including services collective accommodation facilities (almost 33\%) make considerable share in a structure of paid services in the Yaroslavl region. Unfortunately, the share of paid services in hotel complexes of the region makes up only about $3 \%$ proving a significant unused reserve for the tourism industry development in the Yaroslavl region (Department of tourism development in the Yaroslavl region, 2014).

The economic-political potential of development of the regional tourism industry is connected with the fact that the Yaroslavl region is economically developed region of Russia and takes leading positions in the Central Russia according to many parameters of social and economic development. The Yaroslavl region has considerable and various industrial and transport potentials which notably define prospects of the region development. The main advantages of the Yaroslavl region are well-balanced structure of its economy and "manufactures-stabilizers" (oil refining, petrochemical industry, car industry). The Yaroslavl oblast belongs to industrially developed region specializing on petrochemical industry and mechanical engineering.

The growth of Gross Regional Product per capita in the Yaroslavl region makes up 5\% at the average in the recent three years. More than $60 \%$ of the functioning enterprises are profitable (Analytical report about social and economic situation and condition of labour market of the Yaroslavl region according to results of labour market monitoring as of 01.01.2013, 2014).

Fiscal capacity of the region is about 1, with a stable credit rating (Stable condition of the Yaroslavl region economy, 2013).

Social and political situation in the region within the period of monitoring remained relatively stable and did not influence on criminogenic conditions much. This promotes tourism development in the region. 2186 public events with large-scale involvement of citizens were held in the region from the beginning of 2013. These events included 130 sports events, 354 political events, 741 mass cultural events, 900 religious events, and 61 events of other types. About 1.9 million people took part in the events in total (Condition of social and economic, operational situation and the main results of office activities of Regional Office of the Ministry of Internal Affairs of the RF in the Yaroslavl region for 12 months of 2013).

Demographic and human resources potential influences on the development of the Yaroslavl region tourism market as well.

The experts suppose that population of the Yaroslavl region will increase on 651 persons in 2015; the population increase will include 555 villagers and 196 city dwellers. Birth rate increases as well: increase of birth rate makes $3.3 \%$ or 380 persons annually at the average within the recent 15 years (from 1997 until 2012). The death rate reduces: death rate is reduced by $0.3 \%$ or 97 persons annually at the average within the recent 15 years. The number of people arriving to the region exceeds the number of people leaving the Yaroslavl region for many years. (Analytical report about social and economic situation and condition of labour market of the Yaroslavl region according to results of labour market monitoring as of 01.01.2013, 2014).

At the same time, the region has widely developed system for training of professional personnel for the tourism 
industry. The regional high schools train specialists of the following spheres: "Tourism", "Service", "Hotel business" etc.

Educational institutions in systems of higher, average and additional vocational education train personnel for the tourism industry. Regional vocational training included 29 educational institutions at the beginning of 2013/2014 including branches. The system of these institutions consists of 8 institutions of higher education and 21 institutions of secondary-level education (The regional program of additional measures for reducing of tension in the Yaroslavl region labour market for 2013-2015, 2013).

In the Yaroslavl region, the professionals of the tourism sphere are trained mainly in institutions of secondary vocational education. Educational institutions of secondary vocational education offer the following studying directions: "Hotel service", "Service in public catering", "Applied and decorative arts and folk crafts", "Tourism", "Food technologies of public catering", "Organization of public catering service", "Tourism expert".

Taking into account the basic problems of the personnel potential realization, education system improvement is required in the following direction of the tourism business:

- Development of concept for continuous vocational education in the tourism sphere including creation of branch priorities for qualifications and competences, formation of professional standards for workers of the tourism industry, development and improvement of branch system for assessment and certification of qualified employees of the tourism industry (certification of guides, hotel workers, etc.);

- Promotion of integration of tourism education, science and tourism industry in order to create highly competitive Russian market of tourism;

- Formation of educational institutions of a new type within the scope of network interaction (secondary education - higher education - organization-employer) which would be the innovative centres of practice - oriented education;

- Regular monitoring of tourism sphere workers, formation of state orders for training and upgrading of professional skills of experts working in the tourism sphere;

- Rating assessment of educational institutions with participation of employers in order to provide consumers with trustworthy information about condition of labour market and educational services in the tourism sphere;

- Improvement of education programs and materials for specialities of the tourism industry (in particular, programs of education, retraining and upgrading of professional skill of guides and interpreters, attendants in the tourism sphere);

- Development of models for social prediction of scenarios of the tourism branch development;

- Focusing of subjects of degree works composed by students of the tourism sphere specialities on themes promoting development of the tourism industry in the Yaroslavl region;

- Promotion of partnership between subjects of the tourism industry and educational institutions offering specialities of the tourism sphere, in order to ensure effective employment of experts.

Thus tourism and potential of the Yaroslavl region interact between each other, are interdependent and complementary which creates a basis for positive improvement of tourism sphere and expansion of its influence on the regional labour market.

The analysis of a modern condition of the tourism industry in the Yaroslavl region shows that tourism took the second place among the reasons of arrival to the region in 2013 (Figure 4) (Monitoring of consumption of services in the sphere of tourism business of the Yaroslavl region, 2013). 


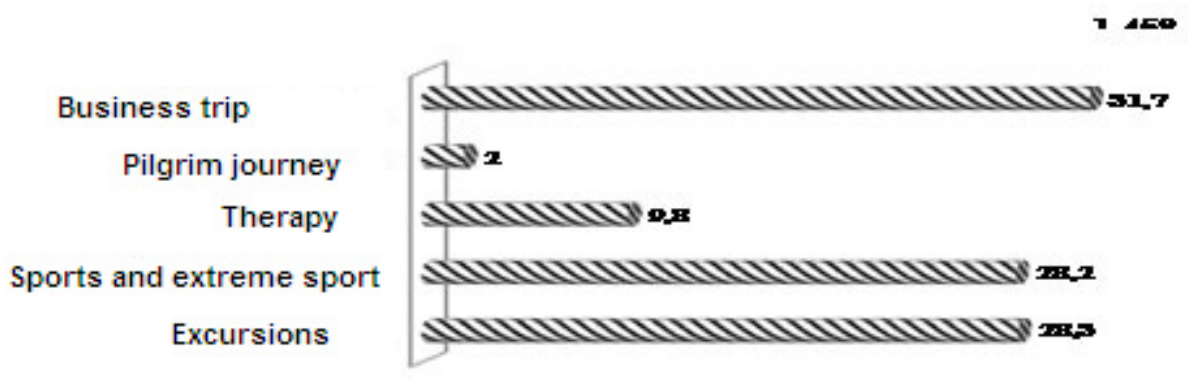

Figure 4. Purposes of tourists' trips in the Yaroslavl region in $2013(\%)$

Quantitative changes can be observed in tourist accommodation services. According to the Yaroslavl statistics office, the number of travel agencies and hotel enterprises has considerably increased in the recent years. In 2012, their number made 74 and 52. In 2013, there were already 109 and 63 of such enterprises respectively. Influence of the tourism industry on social and economic development of municipal units of the Yaroslavl region is shown in such an important indicator as local population employment. About 7.5 thousand persons work in the tourism industry, about quarter of them-in the Yaroslavl city (Regional office of the Federal agency of the state statistics in the Yaroslavl region, 2014).

Thanks to activity of all subjects of the tourism industry, organizational work of the governmental structures, results-oriented advertising-information and marketing policy for promotion of the regional tourism product, the number of tourists visiting the region increases continuously. There are 17 tour operators in the market of inbound tourism. Each one of them serves more than 1000 persons annually. Tourist stream in the Yaroslavl region has grown almost in 4 times in the recent 9 years (Figure 5). Thus, the stream of foreign tourists has grown on $25 \%$. More than $40 \%$ Russian and almost $10 \%$ of foreign guests visit the Yaroslavl region again (Monitoring of consumption of services in the sphere of tourism business of the Yaroslavl region, 2013).

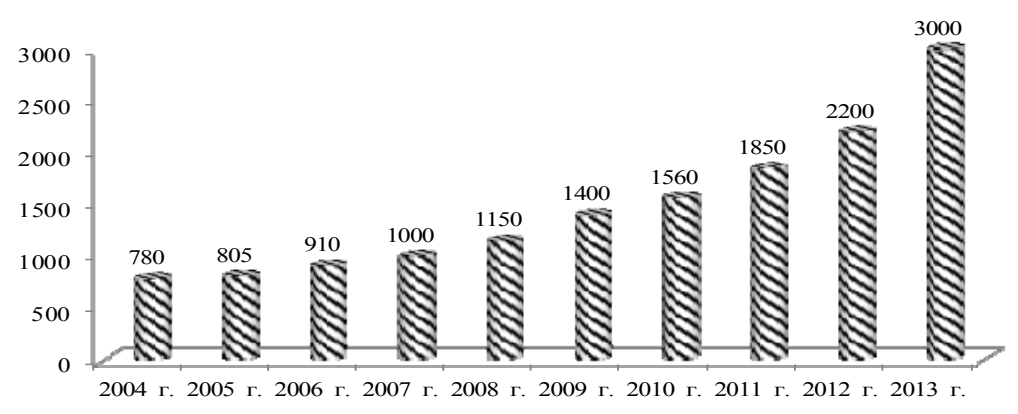

Figure 5. Quantity of tourists in the Yaroslavl region, thousand people

In 2012, the most tourists ( $66 \%$ of total) were citizens of Russia. The main countries, which are sources of inbound tourism: France (34\%), Germany (27\%), the USA (14\%), Italy (6\%), Great Britain (5\%). France continues to take to first place in the stream of inbound tourism, but in comparison with the previous year, its share was reduced by 7 percent. The number of tourists from the USA has contrariwise increased on 7 percent. The share of tourists from the CIS countries is insignificant and makes less than $1 \%$ of the total amount of tourists. In 2012, the stream of tourists from the CIS countries was reduced twice in comparison with 2009 year (Monitoring of consumption of services in the sphere of tourism business of the Yaroslavl region, 2013).

It is necessary to stress that interest of foreign tourists to various subjects of the Russian Federation is non-uniform. Leading positions in quantity of foreign guests are taken by Moscow, St. Petersburg, Central, Southern, Far Eastern and Northwest federal districts. St.-Petersburg and Northwest federal district constantly have the leading positions of the foreign tourists' quantity. First, it is connected with various attraction objects and sights, developed infrastructure, closeness to state borders. It should be mentioned that this region is 
traditionally more focused on tourism, than the regions of the Central federal district. The Yaroslavl region takes the 4th place in quantity of foreign tourists in the Central federal district. The first three places are taken by Moscow, Vladimir and Kaluga regions. In particular, in 2013, 3 million tourists visited the Yaroslavl region (The Federal Agency for Tourism, 2014).

It is necessary to emphasize development of business tourism, water touring, primary wellness tourism, rural and social kinds of tourism among the latest trends of the tourism industry.

Despite of insignificant increase of business tourists' quantity, the share of business tourism is reduced in total amount of tourism arrivals. In 2008 their relative share made $35.3 \%$ of the total amount of tourists. However, the share of business tourists was reduced to $22.4 \%$ in 2012. Considerable growth of number of business tourists in 2009 (on $26 \%$ ) was caused by business events organized shortly before the 1000th anniversary of Yaroslavl city. Positioning of Yaroslavl and Rybinsk as centres of the international level and carrying out of large world forums attracts business tourists to the Yaroslavl region and promotes development of the whole tourism sphere and infrastructures connected with it (Monitoring of consumption of services in the sphere of tourism business of the Yaroslavl region, 2013).

Water touring. The statistics of tourists making a boat tour in the Yaroslavl region reflects certain trends of development of water touring in the Yaroslavl region. The growth made $24 \%$ in the period of 2009-2012 (Figure 6) (Monitoring of consumption of services in the sphere of tourism business of the Yaroslavl region, 2013).

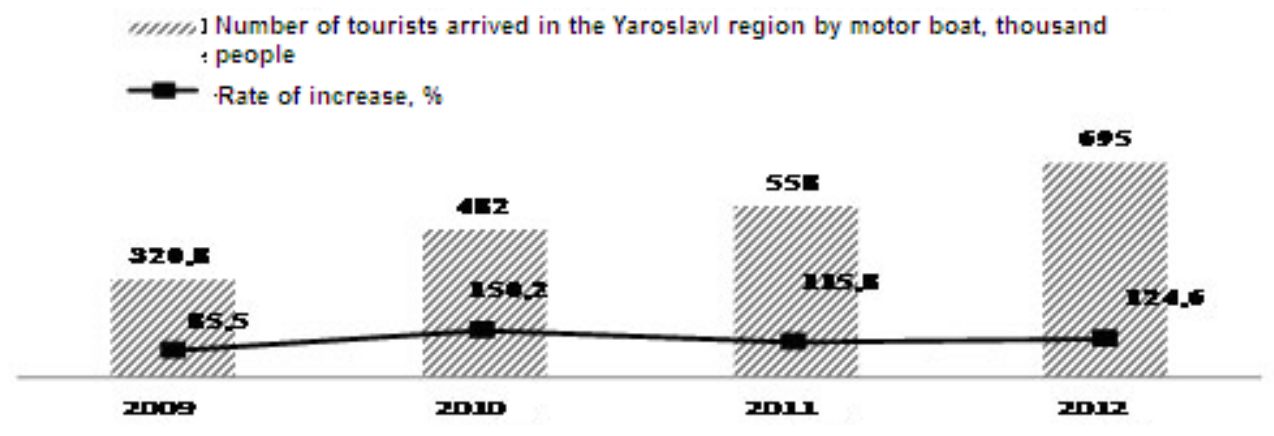

Figure 6. Indicators of water touring development in the Yaroslavl region

Since cruise travel is one of the most expensive kinds of tourism in the world, it is more dependent on the level of purchasing power of the travellers than any other type of tourism. This is the reason of reduction of the tourists' stream in 2009. In the subsequent years, the tourists' stream has reached the previous level and significantly exceeded the level of 2009.

The potential for development of water touring in the Yaroslavl region is big. Five cities and one urban-type settlement are situated on the great Volga River (Yaroslavl, Rybinsk, Uglich, Myshkin, Tutaev, Nekrasovsk settlement). The river runs $340 \mathrm{~km}$ over the region territory. There are two water basins on Volga River in the region: Uglich and Rybinsk.

More and more people choose independent water travels across Volga River on small vessels and yachts. Generally, the most yacht-clubs and recreation camp are concentrated in five areas located on Volga River and Rybinsk water basins. Foundation of new, modern yacht-clubs promotes development of not only water touring, but also connected types of tourism and recreational activities.

Primary wellness tourism is one of segments of the Yaroslavl region tourism market. Its development has contradictory trends. On the one hand, the Yaroslavl region has high recreational potential; natural tourism resources are highly attractive. On the other hand, despite of the great history of primary wellness tourism, its industry reduces.

Primary wellness tourism in the Yaroslavl region can become a priority kind of tourism only after updating of a life cycle of this tourism product. Taking into account existing recreational potential, as well as outlined development of pharmaceutical cluster, base for training of medical personnel, and history of development of the primary wellness tourism in the Yaroslavl region, it makes sense to consider big investment and financial support of this sphere of tourism with the account of increasing requirements of the Russian and foreign citizens.

Rural tourism is a new segment for the tourism sphere of the Russian Federation. In the Yaroslavl region, its 
development is limited because of poor offer. According to Tourism Agency of the Yaroslavl region, the rural tourism base consists of only three objects. However, in the light of growing interest to this kind of travels, rural tourism should be considered as promising for the Yaroslavl region. Integration of peasant farm enterprises into tourism sphere, information and methodological assistance in formation of the tourism product in countryside can become the base for its development.

As it was already mentioned, the tourism branch has a strong multiplied impact on increase of employment level in the region. These results not only from increased number of workplaces, but also from the positive influence of various allied industries, which promote growth of the regional labour market: public catering, transport, services, culture and leisure activities, etc. It is usual for the international practice to calculate both direct and indirect effect of tourism on Gross Regional Product. Taking into account indirect effects, development of tourism and related business should provide at least $10 \%$ of Gross Regional Product of the Yaroslavl region by 2025. This indicator can be reached by compilation of three components: formation of conditions for effective and rapid development based on exactly defined priorities (Figure 7) (Internet portal of public authorities of the Yaroslavl region, 2014). Taking into account priority of development of the Yaroslavl region tourism industry, the role of state regulation of tourism development has become much more important today. This arises from influence of the state on economic entities, namely providing conditions for effective functioning of the market mechanism in the region, implementation of state social and economic priorities and formation of the uniform tourism industry development concept.

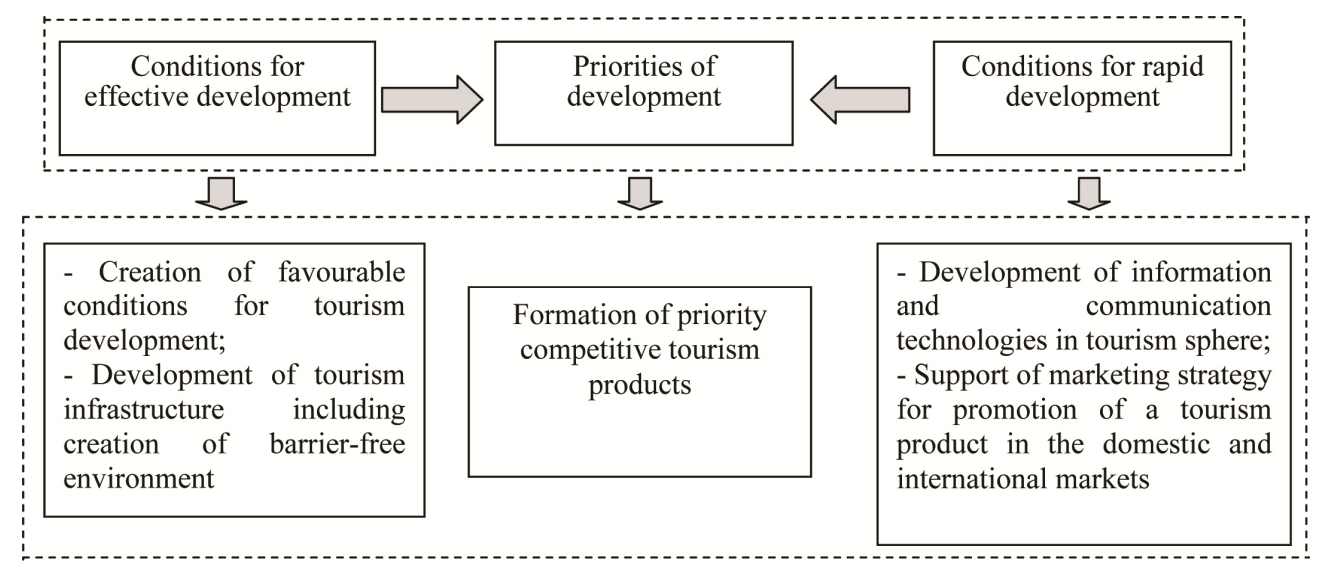

Figure 7. Components of strategy for priority development of the Yaroslavl region tourism sphere

This is a complex process, which includes development of state policy for regulation and promotion of tourism, underpinning of its goals, tasks, main directions, selection of tools and methods for realization. The main workload for formation and realization of priority directions of tourism state regulation in the Yaroslavl region rests on the regional Tourism Agency and relevant departments of Administration of the Yaroslavl region.

\section{Discussion}

Thus, the research showed that the tourism industry in the Yaroslavl region which modern state proves the positive trend of development is a strategic priority promoting increase of employment level in the region. It shall be mentioned that tourism will influence on the labour market only at increased scope of the tourism industry, which is proved by dynamics of integrated indexes (Figure 8). 


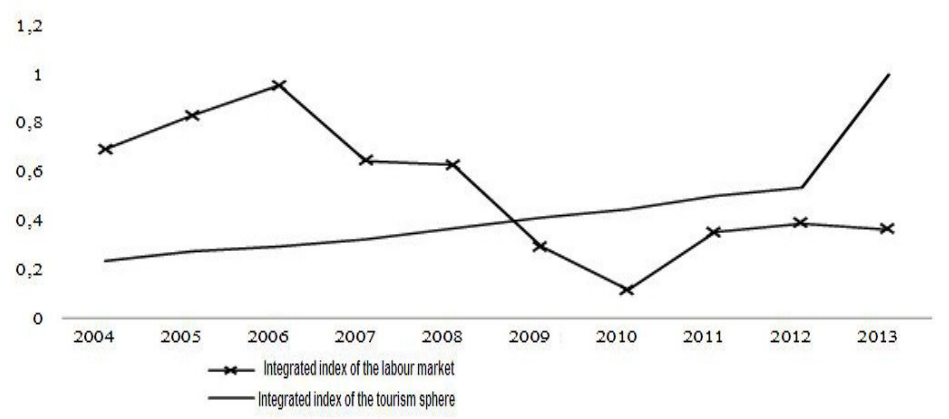

Figure 8. Taxonomic indexes of developmental character of the tourism and labour markets in the Yaroslavl region

Research of performance features of the tourism market in the Yaroslavl region taking into account background of its formation and development, show destabilizing factors of the tourism industry as key sphere of employment level in the region.

Lack of the positive information about the country, no advertisements of Russia in the foreign markets, war in the Chechen Republic in the late nineties, terrorist attacks in Moscow, conflicts with Ukraine and other states resulted in the fact that Russia was brought to the list of directions which are not recommended for tourist trips.

The average depreciation ratio of hotel basis in the Yaroslavl region makes up almost $70 \%$ today (Department of tourism and regional strategy of the Ministry of culture of the Russian Federation, 2014).

Lack of favourable conditions for investments into tourists' accommodation and other tourism infrastructure.

Visa regime in the Russian Federation, which is unfavourable for tourist trips. Overestimated cost of visas, long terms of their issuing and other consular restrictions complicate visiting of Russia by the foreign tourists, which tend to make decision of a trip shortly before a planned departure date.

Low level of service, mismatch of prices for the offered services with their quality (especially quality of accommodation, catering and transport conditions) in the Yaroslavl region. Today the service of international level is offered only by high quality hotels in Moscow and St. Petersburg.

Problem with training of the relevant personnel. The gap between requirements of the tourism branch and the offer of educational institutions is quite big. The main problems of the tourism personnel potential in the Yaroslavl region are:

- Gap between a theoretical orientation of vocational training of the tourism sphere workers and real requirements of the market. The professional training sector does not meet the requirements of the tourism industry in quantitative and qualitative senses (lack of professional personnel of the hotel business sphere is now observed in the Yaroslavl region);

- Poor interaction between educational institutions and employers. At the best case interaction is realized only by undergraduate training of students and single invitations of representatives from travel agencies and hotel business to teach at high school;

- Lack of regular monitoring of need of tourism, hotel and accompanying business enterprises for experts of various qualifications;

- Lack of professional teachers training students for the tourism sphere (the majority of teachers have no work experience in the tourism sphere);

- Poor material and methodical base of vocational training institutions in the tourism sphere.

It is necessary to stress the following nuances among the basic directions of development and improvement of the tourism industry in the Yaroslavl region and promotion of influence of this branch on the regional labour market.

Creation of favourable investment and financial conditions for development of tourism in the Yaroslavl region. 
It is necessary to introduce more flexible and stimulating state regional tax and credit policy in order to attract foreign and domestic investments into development of the tourism industry in the Yaroslavl region.

Support of marketing strategy for promotion of the Yaroslavl region tourism product at domestic and international levels.

A brand-book of the Yaroslavl region should become the unique multimedia project supporting and reflecting the regional "symbolical assets". The project should include the most significant attributes of the region in the field of history, sports, arts, pop culture, politic, economy, industry, fashion and many other life spheres. This should not be an ordinary encyclopaedia about the Yaroslavl region. The brand-book is a synergy of art, ads and new technologies.

Development of information and communication technologies in tourism sphere. We propose to develop and introduce a system of information and tourist's navigation in order to provide information support of tourism, increase awareness of tourists about tourist attractions of the Yaroslavl region. In order to achieve this goal it is necessary to equip highways and roads with multilingual markings with a name of tourist attraction and distance to it. Tourist maps with designation of the main tourist routes including rational routing should be developed and placed in the region's territory. It makes sense to place maps on parking places (for example, gas stations) at entrance to the region's territory. World trends of the tourism development show increase of number of independent tourists. Promotion of the Yaroslavl region as tourist region, support of strategic target to make the region of ten leading tourist centres of Russia should begin with creation of comfortable environment for different categories of tourists. For this reason, multilingual information stands about tourist attractions (historical, cultural, and religious monuments) shall be included to the first stage strategic measures list. Such practice is wide spread among the world's leading tourism centres.

Many investment projects, which create new workplaces in the tourism sphere, are being realized in the Yaroslavl region currently. It is planned to create 3 thousand new workplaces by 2018 as a part of "Golden Ring" project; and about 2 thousand workplaces - as a part of "Yaroslavl shore" project (Government program of the Yaroslavl region "Development of culture and tourism in the Yaroslavl region" for 2014-2018, 2014).

Full-scale implementation of these projects in order to solve the problem of the Yaroslavl region labour market will be possible only after development and introduction of fundamentally new and effective mechanisms of stimulation of investment activity in the tourism industry. The examples of such mechanisms are: transfer of the management of certain directions of tourist activity to specialized private operators with protection of their social load on principles of state-private partnership; optimization and outsourcing of non-core enterprises and enterprises providing implementation of separate functions of tour package (supply, transportation, catering, cleaning, repair etc.) by specialized private operators; use of sub-contracting in the fields of information, scientifically, and methodical support of tourism, attraction of specialized organizations of this sphere; property support including allocation of premises with developed infrastructure for creation of tourism centres, entertaining complexes, objects of the tourism industry on their base; allocation of office premises on favourable terms in order to support activity of tourist and information centres, attraction of leading operators of the tourism industry and MICE-industry.

\section{Conclusion}

The research has shown that implementation of effective employment policy in the Yaroslavl region for support of a stable situation on the labour market requires account of regional features of the territory, i.e., potential for the tourism industry. Tourism is one of the key fields of activity of the region. Increase of financial and human resources potential, diversification of quality and kinds of tourism services, improvement of infrastructure and competence of personnel occupied in tourism business allowed making an essential impact on employment level in the region.

Potential opportunities for comprehensive development of the tourism market in the Yaroslavl region taking into account regional infrastructure features were defined and analysed in the research. The potential opportunities include natural and geographical, culture-historical, professional and demographic, social and economic, material and technical, and economic-political potentials.

A proportional regular dependence between employment level and tourism industry in the region was defined based on their modern condition. The main destructive factors for development of tourism in the Yaroslavl region were revealed. Recommendations for creation of favourable conditions for tourism development including increase of employment level in the Yaroslavl region were developed. It is supposed that implementation of the offered complex of measures will allow promoting improvement of the tourism industry 
and services sphere which will positively influence employment level in the region and will create a theoretical basis for further scientific researches in this field.

\section{References}

Akkemik, K. (2012). Assessing the importance of international tourism for the Turkish economy: A social accounting matrix analysis. Tourism Management, 33, 790-801. http://dx.doi.org/10.1016/j.tourman.2011.09.002

Analytical report about social and economic situation and condition of labour market of the Yaroslavl region according to results of labour market monitoring as of 01.01.2013. (2014). Retrieved from http://resurs-yar.ru/files/analit_spravka.pdf

Asalieva, A. et al. (2013). Economy and management of human resources. Scientific research centre "Infra", 323.

Blanke, J., \& Chiesa, T. (2013). The Travel \& Tourism Competitiveness Report 2013. Reducing Barriers to Economic Growth and Job Creation Reducing Barriers to Economic Growth and Job Creation. Insight Report. World economic forum. Retrieved from http://www3.weforum.org/docs/WEF_TT_Competitiveness_Report_2013.pdf

Brida, J. et al. (2010). Causality between Economic Growth and Tourism Expansion: Empirical Evidence from Trentino. Alto Adige. TOURISMOS: An International Multidisciplinary Journal of Tourism, 5(2), 87-98.

Chernenko, V., \& Arapova, L. (2007). The market of tourism services in the conditions of integration of Russia in the world economy (p. 160). St. Petersburg: Saint-Petersburg State University of Economics.

Condition of social and economic, operational situation and the main results of office activities of Regional Office of the Ministry of Internal Affairs of the RF in the Yaroslavl region for 12 months of 2013. (2013). Regional Office of the Ministry of Internal Affairs of the RF in the Yaroslavl region. Retrieved from https://76.mvd.ru/

Department of tourism and regional strategy of the Ministry of culture of the Russian Federation. (2014). Retrieved from http://mkrf.ru/ministerstvo/departament/list.php?SECTION_ID=19314

Department of tourism development in the Yaroslavl region. (2014). Retrieved from http://www.adm.yar.ru/econom/pr_tr/tourism/

Expert RA Rating Agency. (2014). Retrieved from http://www.raexpert.ru/

Government program of the Yaroslavl region "Development of culture and tourism in the Yaroslavl region" for 2014-2018. (2014). Tourism Agency. Retrieved from http://www.yarregion.ru

Gulyaev, V. (2012). Tourism: Economy and social development. Finance and statistics, 2003, 304.

Hughes, G. (2002). The employment and economic effects of tourism reappraised. Tourism Management, 167-176.

Internet portal of public authorities in the Yaroslavl region. (2014). Retrieved from http://www.yarregion.ru/Pages/p_601.aspx

Kovyneva, L. (2005). Regional tourism (p. 111). Khabarovsk: Publishing house of the Far Eastern State Transport University.

Monitoring of consumption of services in the sphere of tourism business of the Yaroslavl region. (2013). Tourism Agency of the Yaroslavl region. Retrieved from http://www.yarregion.ru/depts/Tourism/default.aspx

Official target program "Assistance for employment of the population of the Yaroslavl region" for 2014-2015. (2014). Internet portal of public authorities of the Yaroslavl region. Retrieved from http://www.yarregion.ru/default.aspx

Ponomarenko, A. (2014). Illegal business in figures. Forbes. Retrieved from $\mathrm{http}: / / \mathrm{m}$.forbes.ru/article.php?id=65945

Regional office of the Federal agency of the state statistics in the Yaroslavl region. (2014). Retrieved from http://yar.gks.ru/

Regional target program for development of tourism and recreation in the Yaroslavl region for 2011-2014. (2011). Tourism Agency. Retrieved from http://www.yarregion.ru/depts/der/docsPrograms/2_tur.doc 
Savelyeva, Y. et al. (2008). Management of tourism development in the region. Experience of implementation of the Republic of Karelia Strategy (p. 141). Petrozavodsk: Publishing house of the Karelian scientific centre of the Russian Academy of Sciences.

Stable condition of the Yaroslavl region economy. (2013). Retrieved from http://www.tpp-inform.ru/news/13287.html

The Federal Agency for Tourism. (2014). Retrieved from http://www. russiatourism.ru/

The regional program of additional measures for reducing of tension in the Yaroslavl region labour market for 2013-2015. (2013). Internet portal of public authorities in the Yaroslavl region. Retrieved from http://www.yarregion.ru/default.aspx

Tourism Agency. (2014). Retrieved from http://www.yarregion.ru/depts/Tourism/default.aspx

Tourism, Economic Growth \& Employment. (2006). Research and Economic Programming Division. Bank of Jamaica. Working Paper. Retrieved from http://www.ccmfuwi.org/files/publications/conference/918.pdf

Vanhove, N. (1981). Tourism and Employment. International Journal of Tourism Management, 2(2), 62-175.

Voskolovich, N. et al. (2010). Tourism in a changing world (p. 141). Economics department of the Moscow State University.

\section{Copyrights}

Copyright for this article is retained by the author(s), with first publication rights granted to the journal. This is an open-access article distributed under the terms and conditions of the Creative Commons Attribution license (http://creativecommons.org/licenses/by/3.0/). 